\title{
Modernismo/Hipermodernismo: o debate teórico italiano contemporâneo
}

\author{
Leonardo Ferreira Aguiar*
}

\begin{abstract}
Resumo
O presente artigo tem por objetivo trazer ao debate literário brasileiro a discussão em andamento na crítica literária italiana sobre o que críticos atuantes compreendem como Hipermodernismo, ou seja, uma literatura cujos escritores retomam as bases do modernismo de maneira a querer dar forma a uma experiência conturbada no século XXI. Para ilustrar o debate, apresentar-se-á a perspectiva de dois críticos italianos contemporâneos: Raffaele Donnarumma e Remo Ceserani, cujos textos conflitam em relação ao que se entende por termos como "modernidade", "modernismo", "pósmoderno", "pós-modernismo" e, enfim, "hipermodernismo". Acredita-se que essa discussão possa agregar aos estudos na área da literatura brasileira e oferecer novos pontos de vista que permitam analisar o Modernismo e a literatura contemporânea de nosso país.

Palavras-chave: Modernismo. Hipermodernismo. Literatura brasileira. Literatura italiana.
\end{abstract}

* Universidade de São Paulo (USP). Mestrando do Programa de Pós-Graduação em Língua, Literatura e Cultura Italianas da USP. ORCID: https://orcid.org/0000-0001-9659-5341. 


\title{
Modernism/Hypermodernism: the Italian contemporary debate
}

\begin{abstract}
This article has as its goal to bring to the Brazilian literary debate a current discussion in the Italian Literature critic about what the actual specialized critics understanding as Hypermodernism, which is, a literature which writers return to the bases of the Modernism willing to build a form to a troubled experience in the $21^{\text {th }}$ century. To illustrate the debate we intend to present two Italian contemporary critics' perspective: Raffaele Donnarumma and Remo Ceserani, which articles conflict in what they understand by words such as "modernity", "modernism", "post-modernity", "post-modernism" and, at last, "hypermodernism". We believe that this discussion may collaborate to the Brazilian Literature area of studies and offer new points of view that allow to analyze the Brazilian Modernism and its contemporary literature.
\end{abstract}

Keywords: Modernism. Hypermodernism. Brazilian Literature. Italian Literature.

Recebido em: 13/09/2021 // Aceito em: 27/11/2021. 


\section{Introdução}

No ano de 2022 será festejado o centenário do Movimento Modernista no Brasil, cujo palco primeiro foi o Theatro Municipal, na cidade de São Paulo, capital do Estado homônimo. Ainda que parte da cultura brasileira, o Modernismo ainda é visto, pelo senso comum, como um período unitário o qual, apesar das consideradas três fases, teve seu começo, meio e fim. Trata-se do velho problema da classificação típica de manual escolar de dividir os movimentos artísticos e culturais em "escolas", causando a sensação de que há uma interrupção entre uma e outra, como se não houvesse relação entre o acúmulo de experiência e a inovação nos paradigmas. Sendo assim, o primeiro mito ao qual precisamos ir de encontro é o de considerar não apenas um Modernismo, mas, sim, compreender que este é um termo que abriga em si várias expressões ou, melhor dizendo, vários modernismos.

As contribuições das vanguardas europeias são flagrantes nos modernismos brasileiros, sendo que o próprio Movimento Antropofágico tinha como base, justamente, "devorar" o outro, ou seja, apreender e inovar a partir de técnicas, concepções e estéticas que, no velho continente, já estavam em vigor de maneira igualmente plural e dinâmica. Um exemplo disso é a relevância que teve o Manifesto Futurista, do italiano Felippo Tommaso Marinetti (1876-1944), em Oswald de Andrade (18901954), um dos protagonistas da Semana de 1922. Nesse sentido, o segundo ponto para o qual acenamos é que a observação e o conhecimento do que se produzia na Europa fomentou uma geração de artistas e intelectuais brasileiros que trabalharam essas ideias e materiais à luz do posicionamento como brasileiros 
e desenvolveram os seus próprios trabalhos a partir de um ponto de vista formal e crítico.

Das duas observações acima, surge uma terceira, que aponta para os modernismos europeus não como movimentos oriundos de diletantismos, mas de uma busca por uma forma que fosse capaz de expressar o que a tecnologia e a dinâmica social do novo século (então, o séc. XX) trazia. Logo, ao falarmos sobre modernismos europeus, é lícito dizer que pensamos em uma questão estética, formal e de experimentação, cujos procedimentos de uma literatura modernista fazem-se presentes, por exemplo, na resposta às tensões que desaguaram na Primeira Guerra Mundial e à experiência do conflito armado propriamente dito, modificando a percepção do que seria a experiência humana em um tempo e em um espaço dilacerados pelo horror. Conforme Anatol Rosenfeld sintetiza, "nota-se no romance [do século XX] uma modificação análoga à da pintura moderna, modificação que parece ser essencial à estrutura do Modernismo. À eliminação do espaço, ou da ilusão do espaço, parece corresponder no romance a da sucessão temporal." (ROSENFELD, 2009, p. 80). A relativização do tempo e do espaço, categorias anteriormente progressivas e basilares de uma ordenação tradicional do romance - para continuar no exemplo -, logo abre espaço à percepção da consciência sobre o mundo, que põe em dúvida "uma ordem que já não parece corresponder à realidade verdadeira" (ROSENFELD, 2009, p. 81).

Se o que dissemos for verdade, também podemos afirmar que, hoje, 100 anos depois dos modernismos europeus e à porta do centenário da Semana de Arte Moderna no Brasil, o mundo parece replicar tensões análogas às do início do século passado, sendo que as guerras no Oriente Médio, a pandemia do novo 
Coronavírus, a guinada generalizada ao conservadorismo e ao totalitarismo e afins são vetores que expõem uma ferida a qual se acreditava ter cicatrizado há pelo menos 30 anos, com o fim da polarização da Guerra Fria. Uma vez que se cria um cenário propício de tensões, hiperbolicamente aumentado pelas novas tecnologias digitais, emerge, na literatura, um tipo de escrita que retoma os modernismos como base, resultando em um "retorno" modernista. Exemplo disso é a literatura italiana contemporânea, cujos escritores parecem compartilhar de características formais e temáticas que nos permitem aglutinálos em um grupo conhecido por parte da crítica como scrittori degli anni zero (escritores dos anos zero), ou seja, uma geração que atua no cenário literário do século XXI e que, em suas obras, lança um olhar que mistura tradição e inovação sobre o presente.

Logo, tomando a literatura italiana como exemplo, o objetivo deste artigo é apresentar o debate na crítica italiana contemporânea sobre a literatura dita dos "anos zero" e, brevemente, quais seriam as suas características, pois, uma vez que identificamos a presença europeia na arte modernista brasileira no século XX, hoje essa nova literatura pode trazer indícios do que podemos esperar (ou do que já podemos identificar) na literatura brasileira atualmente.

\section{Moderno/Pós-Moderno, Modernismo/Pós-Modernis- mo e Hipermoderno}

A questão de quando começam os "anos zero" leva a uma série de debates vívidos e plurais em curso por pelo menos uma década no âmbito da crítica italiana. Um exemplo interessante para abordarmos o tema são as discussões em formato de artigos, 
ensaios e resenhas que circulam na revista Allegoria, uma revista italiana online de crítica literária organizada e editada por Massimiliano Tortora e Romano Luperini. Especialmente, em seu número 64, ${ }^{1}$ de 2011, todas as publicações na seção principal são dedicadas ao tema da letteratura degli anni zero, ocasião na qual se discute a perspectiva de uma literatura italiana nova e atuante no século XXI, bem como o papel do crítico na atualidade, o mercado editorial em um contexto altamente tecnológico e informatizado e o corrente predomínio da prosa em relação à poesia. Tais temas são debatidos por nomes importantes da crítica e do meio universitário, como Gianluigi Simonetti, Andrea Cortellessa, Romano Luperini, entre outros. Tendo sido um dos organizadores e contribuído com esse número da revista, Raffaele Donnarumma, também ele crítico e atualmente professor na Universidade de Pisa, apresentou um texto intitulado Ipermodernità: ipotesi per un congedo del postmoderno (2011), o qual, mais tarde, seria reescrito e republicado como o terceiro capítulo de seu livro Ipermodernità: dove va la narrativa contemporanea (2014a).

$\mathrm{O}$ texto em questão reflete sobre a passagem do pósmoderno ao hipermoderno, termo originalmente oriundo das obras do filósofo francês Gilles Lipovetsky (LIPOVETSKY; CHARLES, 2004) e que serve para que Donnarumma faça uma cisão entre dois tempos da literatura, sendo categórico ao afirmar que o pós-moderno acabou e que se trata já de um consenso, sendo que, desde a metade dos anos noventa do século XX, pode-se perceber uma mudança no cenário cultural e literário italiano, o que permite dizer que vivemos uma nova etapa, ou seja, da literatura hipermoderna. As ideias do autor merecem ser

1 Disponível em: https://www.allegoriaonline.it/index.php/i-numeri-precedenti/allegoria-n64. Acesso em: 28 ago. 2021. 
esmiuçadas nos detalhes, mas o que nos interessa neste momento é que Donnarumma faz uma importante distinção entre o período histórico dito "pós-moderno" e uma literatura "pós-modernista", podendo dizer, justamente por isso, que o tempo presente, como categoria historiográfica, ainda é o pós-moderno, enquanto que a literatura já é hipermoderna. Ainda, afirma que essa nova forma de escrever no presente desponta nos EUA e na Europa, mas com ainda mais vigor na Itália porque, assim como o país foi um dos primeiros a registrar tendências pós-modernas, também agora exprime "uma cultura literária particularmente sensível à mutação da qual estamos participando [...]" (DONNARUMMA, 2011, p. 50, tradução nossa). Essas mudanças sobre as quais o crítico fala partem da metade dos anos 1990, cuja data simbólica seria a ascensão de Silvio Berlusconi como primeiro-ministro italiano, em 1994, momento no qual se começa a sentir o peso, justamente, de um cenário mundial globalizado, herdeiro de um neoliberalismo brutal e do fim da polarização ideológica com a derrocada do comunismo e da URSS. Nesse período inaugurase uma nova forma de escrever com Scuola di nudo (1994), de Walter Siti, e que, recentemente, encontra maturidade em livros como Gomorra (2006), de Roberto Saviano, para citar um caso emblemático.

Assim, é possível perceber que "anos zero", na perspectiva de Donnarumma, não corresponde à última virada de século; e, mesmo que não seja ainda uma categoria historiográfica e da crítica literária, nota-se que o hipermoderno começa bem antes do século XXI: se o livro de Siti de 1994 é a primeira obra italiana que poderia ser considerada hipermoderna, desde meados dos anos 1970, já se podem notar os sinais de uma mudança de perspectiva nos escritores, como em Fils (1977), 
do francês Serge Doubrovsky (DONNARUMMA, 2011, p. 3132). Logo, criar uma categoria ligando "anos zero" com "anos 2000" é um engano, porque não se trata de fazer coincidir fatos históricos e fenômenos culturais. Reportando as suas palavras, Donnarumma declara:

Fica difícil precisar a relação entre fenômenos culturais e fatos históricos, tanto mais onde cultura e fatos se movem ambos com velocidades diferentes e, em parte, escondem-se umas nas outras. Uma vez renunciado o acaso, história e historiografia literária entram em um regime de analogia ou de concomitância que não tem alguma garantia a priori, mas que continuamos a perceber. Não ocorre, de fato, sermos historicistas vulgares para crer que, apesar de tudo e entre esfacelamentos contínuos, a literatura está na história. (DONNARUMMA, 2011, p. 15, tradução nossa).

Nesse trecho há uma separação essencial entre o que é o tempo como sucessão de fatos históricos, políticos e sociais (algo que pertence à análise histórica, filosófica, sociológica, etc.) e o tempo da cultura, da arte e da literatura (que demandam uma análise em suas partes técnicas e formais). Aqui, cabe o questionamento: dizer que esses tempos não devem se sobrepor implica que as análises literárias devam ignorar o contexto no qual são produzidas?

Podemos afirmar que não: ter em mente que a literatura e o contexto se relacionam e que a crítica não pode ignorar essa perspectiva é dizer que literatura não está fora da realidade. A literatura é uma elaboração, uma leitura com lentes linguísticoestético-formais da percepção do escritor que pode assumir diversas faces e que, por isso, em termos de análise literária, é independente; contudo, ainda assim, ela não nasce e nem sobrevive em um vácuo histórico, sem um contexto, que muda 
de lugar a lugar e de tempos em tempos, com as variações de sua comunidade literária (BRISOSCHI et al., 2013). Não cabe aqui discutir como essa comunidade e seus diversos agentes (autores, leitores, críticos, editores, tradutores, etc.) e instituições (editoras, universidades, mídias sociais, etc.) influem e determinam a relação entre os campos ${ }^{2}$ da literatura e da história, mas reafirmar a necessidade de um olhar que encare a literatura não como uma reprodução do real. Ainda que a resposta pareça ser um consenso entre estudiosos já de algumas décadas para cá, é necessário ampliar a questão para que se possam compreender as nuances da crítica a respeito de como se dá a relação entre texto e contexto.

Isso é importante porque, no texto que temos citado até agora, Donnarumma faz uma afirmação contundente: "anunciado várias vezes, suficientemente rejeitado, colocado em dúvida por cautela ou contrariado por parte interessada, o fim do pós-modernismo já entrou para o senso comum." (DONNARUMMA, 2011, p. 16, tradução nossa). Porém, o leitor fica um pouco confuso ao ver "pós-modernismo", sendo que, na página precedente, o autor fala que foi o "pós-moderno" que acabara ("Em anos passados, dizer que o pós-moderno acabara significava, na verdade, dizer que deveria acabar; anunciar agora uma fase diferente significa também encorajá-la." (DONNARUMMA, 2011, p. 16, tradução nossa)). Ainda, ao longo do texto, citando Carla Benedetti, Donnarumma (2011, p. 16-17) usa "pós-moderno" na acepção histórica e, logo em seguida, faz referência às poéticas do "moderno" e do "pós-moderno". Muito embora seja possível compreender o que se quer dizer e distinguir quando se fala de

\footnotetext{
2 As colocações aqui presentes no que se refere aos vocábulos "agentes" e "campo" derivam da compreensão de Michel Foucault em Microfísica do poder (1978), obra na qual o filósofo explicita como os agente (formadores de opinião, agentes de controle, instituições, etc.) organizam e (in)flexionam os campos sociais, definição profundamente explorada por Pierre Bourdieu, em Sobre a televisão (1996).
} 
períodos históricos e de literatura, captar a ideia de um e de outro durante a leitura demanda, de fato, empenho (sendo necessário recorrer a outros textos seus, por exemplo, aquele em Allegoria $\mathrm{n}^{\circ}$ 57 (DONNARUMMA, 2008) e ao já citado livro Ipermodernità (DONNARUMMA, 2014a)). Já que Donnarumma faz questão de não fazer coincidir o "tempo histórico" do "tempo da literatura", não seria mais preciso utilizar os termos "pós-moderno" e "pós-modernismo" claramente, de modo que não seja possível questionarmos se eles se equivalem ou se exprimem conceitos diferentes?

Esse é exatamente um dos tantos questionamentos que Remo Ceserani, importante e atuante crítico do cenário intelectual italiano, faz ao texto de Donnarumma. No número seguinte da revista Allegoria, 65-66, Ceserani publica um texto na seção Il presente, intitulado La maledizione degli "ismi" (CESERANI, 2012), no qual rebate duramente o método e as ideias para se avaliar o que se considera hipermoderno e o modo equivocado e contraditório pelo qual se teria conduzido a distinção entre uma categoria historiográfica e uma literária. Além de Donnarumma, Ceserani não poupa críticas ao $\mathrm{n}^{\circ} 64$ de Allegoria e aos intelectuais que ali escreveram, reconhecendo que se esse grupo "tem a ambição, atualmente muito rara entre as revistas análogas, de se apresentar como um 'grupo' muito compacto, que enfrenta a situação cultural e literária contemporânea, sobretudo italiana, com interesse, premissas teóricas e escolhas críticas tendencialmente compartilhadas [...]" (CESERANI, 2012, p. 192, tradução nossa), mas que recai no vício historiográfico de, além de "dividir o percurso da história, fazer disso uma espécie de salame fatiado, em blocos cronológicos precisos [...]" (CESERANI, 2012, p. 192, tradução 
nossa).

Ceserani acusa Donnarumma de imprecisão e de confundir "pós-modernidade" e "pós-modernismo" e resolve, então, separar e definir os termos, conforme podemos conferir nos trechos a seguir:

É a velha maldição dos "ismos". Donnarumma, e muitos outros, nas últimas décadas, que tomaram parte nas discussões, na Itália, sobre a condição social e cultural na qual vivemos (e sobre as representações artísticas, literárias, cinematográficas dessa condição), não consegue ser claro na distinção entre pós-modernidade e pós-modernismo: no primeiro caso, como tanto já se repetiu, há uma proposta, que foi levada adiante a partir dos anos oitenta do século passado, de interpretação histórica dos acontecimentos que transformaram fortemente as condições de vida e as atmosferas culturais nos países de capitalismo avançado (e, enfim, gradualmente nos outros), mas sem nunca atingir todas as áreas do planeta, onde há muitos países que nunca conheceram nem mesmo a modernidade e os processos de modernização. Isso foi uma verdadeira discriminação histórica, não fixada em um ano específico, mas muito clara e forte. [...] Quanto ao pós-modernismo, com esse termo deveríamos nos referir, como ocorre com os "ismos", a uma série de movimentos de ideias, a programas e manifestações artísticas, antes de mais nada arquitetônicas e, depois, pouco a pouco presentes em outros campos de atividades, chegando aos excessos e às caricaturas de uma teologia pós-modernista, de uma filosofia pós-modernista, de uma ciência pósmodernista. Como tendência artística e literária, na verdade, o pós-modernismo nunca realmente tomou a forma tradicional de um movimento: no mundo cultural de hoje há cada vez menos espaço para manifestarse, para grupos de vanguarda e para movimentos organizados. Tratou-se de práticas artísticas, fortemente condicionadas pelas transformações contemporâneas da indústria e do mercado cultural, de movimentos e poéticas, pela sua natureza efêmera, que procuraram (de modo confuso) reagir às transformações em curso, 
talvez como intérpretes e porta-vozes. (CESERANI, 2012, p. 193-194, tradução nossa).

Não obstante, Ceserani também vê a necessidade de separar e definir "modernidade" e "modernismo": o primeiro como um período da história que começa no século XIV na Europa Ocidental e que, a partir de transformações econômicas, sociais, políticas e industriais chamadas de processos de modernização, sofre um salto epocale (salto de época) entre os séculos XVIII e XIX; já o segundo indica uma tomada de consciência de artistas e intelectuais no início do século XX, "uma consciência e uma sensibilidade ao novo e à necessidade de dar vazão e expressão àquela consciência, mas também de freá-la e contrastá-la, em alguns momentos de adesão entusiasta, convidando outros a torná-la própria e a compartilhá-la [...]” (CESERANI, 2012, p. 195, tradução nossa).

Desse ponto de vista, o que Ceserani chama de salto é uma perspectiva histórica de ruptura entre uma fase e outra, sendo que a passagem do moderno ao pós-moderno inaugura um novo tempo a partir dos anos 1950-1960, o que nos levaria a falar de dois séculos XX: um que termina depois da Segunda Guerra Mundial e outro que perduraria até os dias de hoje, tendo sofrido diversas mudanças ao longo das décadas. Ao examinarmos esse salto, encontraremos diversos episódios desde as duas Grandes Guerras que demonstram como caminhamos ao século XXI nutrindo procedimentos, estruturas, instituições e, principalmente, tecnologias que desaguaram em um mundo globalizado, cujo paradoxo é ter fronteiras cada vez mais transponíveis (quando se trata do mercado e do consumo) e que, em contrapartida, torna-se cada vez mais desigual e conflituoso. Se o salto que levou à modernidade "do início do século XIX até a metade do 
século XX [teve] muitas datas simbólicas, correspondentes às transformações ocorridas em diversos âmbitos da vida social [...]" (CESERANI, 2012, p. 201, tradução nossa), mas que foram relativamente lentas e tiveram como protagonistas os EUA e a Europa Ocidental, o salto que leva ao pós-moderno foi claro e quase brusco, porque "se deu com uma rapidez muito maior, atropelando de modo quase que simultâneo muitos países e áreas diversas da vida individual e social [...]" (CESERANI, 2012, p. 202, tradução nossa).

Nesse tempo pós-moderno, todos os eventos marcantes que acometeram o planeta - não homogeneamente - foram acompanhados de uma revolução tecnológica que Klaus Schwab chama de a Quarta Revolução Industrial: nas palavras do autor, "a quarta revolução industrial não é definida por um conjunto de tecnologias emergentes em si mesmas, mas [como] a transição em direção a novos sistemas que foram construídos sobre a infraestrutura da revolução digital (anterior) [...]" (SCHWAP apud PERASSO, 2016). Em suma, essa revolução levou a uma mudança nas sociedades no que diz respeito: ao estreitamento do mundo em termos de deslocamento e comunicação, o que afeta a percepção do tempo cronológico e do espaço tangível; à progressiva popularização da tecnologia desde pelo menos a década de $1980^{3}$ e que hoje está à palma da mão, e ao deslocamento de referências em relação ao consumo de produtos e de cultura, uma vez que, instaurado um padrão pelo mercado dominante estadunidense, instaura-se, também, um padrão de necessidade compartilhado por quem pode consumi-lo e por quem não pode - gerando, aliás, frustrações e crise no indivíduo.

E por que isso é importante para Ceserani? O crítico aponta

3 A Apple, por exemplo, foi fundada por Steve Jobs em 1976. 
que essas mudanças drásticas e profundas durante todo o século passado e em progresso ainda hoje reconfiguraram o imaginário coletivo contemporâneo (inclusive dos escritores, de modo tal que a literatura expressa essa nova realidade) e que, portanto, o trabalho da crítica também deve se fazer presente nesse ponto ao não se apartar de conhecer os fatos e as transformações nas condições de produção literária e de buscar compreender os textos operando em contexto. Em suas palavras:

Quem quiser ver os fenômenos sociais assim como são
(e não assim como gostaria) deve empenhar as próprias
forças em conhecê-los, em suas totais complexidades
e contradições. E quem estuda os textos (literários,
artísticos, cinematográficos) produzidos na nova
condição social deve medir não tanto tal aderência (ou
não) à programas de poética, mas sim a sua capacidade
de penetrar no interior da nova realidade e, também,
a capacidade de operar honestamente dentro das
condições sempre mais fortes da sociedade em que se
vive e da organização editorial sempre mais dominada
pela lógica do interesse econômico e do sucesso de
mercado. (CESERANI, 2012, p. 204-205, tradução
nossa).

Indo mais além no ponto de vista de Remo Ceserani, podemos encontrar mais pistas do que ele considera como literatura no tempo presente, na era do mundo globalizado. No prefácio de Letteratura nell'età globale, publicado em 2012 com Giuliana Benvenuti, há o anúncio de uma retomada da discussão sobre a literatura mundial goethiana (Weltliteratur) em termos atualizados: segundo os autores, para discutir literatura, deve-se descolar o eixo da Europa e do Ocidente para uma perspectiva global; dessa maneira, falar de literatura global coloca "a literatura em relação com o processo socioeconômico da globalização [sendo que] aqueles que usam o termo literatura 
global tendem a assumir uma postura crítica em relação aos fenômenos da tecnologização e homologação cultural [...]" (BENVENUTI; CESERANI, 2012, p. 7-8, tradução nossa). Logo, a literatura não está alinhada com a globalização em seus valores de padronização neoliberal e de consumo, pois está perdendo a sua autonomia perante a eles; ela representa, sim, uma forma de resistência e de inovação na comunicação entre as pessoas, inaugurando sempre novas formas de ver a realidade, que "atualiza as novas virtualidades inexpressas que podem, assim, interagir com o real [...]" (WESTPHAL, 2007 apud BENVENUTI; CESERANI, 2012, p. 110, tradução nossa, grifo dos autores). Em outras palavras, falar de literatura global seria uma abordagem crítica para tratar de uma literatura no mundo globalizado no qual a tecnologia, o mercado e o consumo ditam as regras, inclusive para a literatura; para Benvenuti e Ceserani, falar de literatura na era da globalização é discutir e problematizar os processos de globalização em si mesmos.

Ceserani, porém, não cai em contradição, pois horizontalizar "mundo e literatura, literatura e mundo" (BENVENUTI; CESERANI, 2012, p. 7, tradução nossa) não quer dizer que ambos estejam no mesmo plano de análise, mas que há uma relação simbiótica entre texto e contexto e trocas mútuas entre eles. No terceiro capítulo de Letteratura nell'età globale, intitulado, $L a$ letteratura e le sfide dell'età globale, discute-se a definição de literatura analisando-se o trabalho de Pascale Casanova: partindo dos conceitos de Pierre Bourdieu e de Roland Barthes, Casanova busca compreender o funcionamento das instituições literárias, particularmente os prêmios, e como elas orientam "o gosto e a definição mesma de literatura" (BENVENUTI; CESERANI, 2012, p. 101, tradução nossa); e, nesse sentido, ela propõe uma 
duplicidade temporal, um dentro e um fora da literatura, sendo que esta é constituída por um "espaço dotado de leis próprias, de uma geografia própria, de uma 'cronologia diferencial' própria [...]” (BENVENUTI; CESERANI, 2012, p.102, tradução nossa). Em linhas gerais, Casanova não estaria errada e retomaria $o$ que já vimos inclusive com Donnarumma; porém o equívoco, segundo os autores, é que ela teria se concentrado demais na cisão entre os dois tempos, o que levaria a desconsiderar que as propriedades específicas da literatura interagem com o que está "fora" dela, no que diz respeito à sua linguagem formal e estética.

É nesse ponto que, para Ceserani, Donnarumma peca em seu posicionamento, porque não levaria em consideração $o$ diálogo entre texto e contexto tanto quanto seria necessário para fazer crítica:

\begin{abstract}
Eu acredito que as mudanças que atravessaram as nossas vidas e transformaram profundamente o mundo ao nosso redor ao longo das últimas décadas foram, pela sua intensidade e velocidade, traumáticas e desconcertantes, e que isso já explique as nossas dificuldades para aceitálas e compreendê-las. [...] A análise de Donnarumma investe no setor das práticas literárias e nos movimentos intelectuais (prevalentemente italianos) mais no que as grandes transformações históricas. (CESERANI, 2012, p. 207, tradução nossa).
\end{abstract}

Mas não é só isso: como vimos anteriormente na distinção entre o "pós-moderno" e o "pós-modernismo", o escopo de Ceserani também é demonstrar como, em sua opinião, a vontade de criar uma nova categoria para os escritores deste século partindo do fim do pós-modernismo não se sustenta, porque o pós-modernismo nem mesmo existiu como movimento literário strictu senso, como talvez tenha existido como estética comum 
na arquitetura, por exemplo. Isso não significa, porém, que se deva apagar toda a produção cultural, literária e cinematográfica e reduzi-la a mero experimentalismo autorreferencial, como estaria fazendo Donnarumma na ânsia de inaugurar uma nova fase cultural e literária desconsiderando a tentativa de nomes importantes do cinema, do teatro, da literatura, etc. do mundo todo (inclusive do "terceiro"), aqueles que "buscaram representar, com os meios mais variados, com sucesso e com fracasso, cedendo às modas e às regras do mercado e apesar das regras do mercado, as experiências, os dramas, as frustrações derivadas da nova condição de vida [...]" (CESERANI, 2012, p. 211, tradução nossa). A provocação vai além e Ceserani chega a recordar a Donnarumma os nomes de Nabokov, Pynchon, De Lillo, Vonnegut, Tournier, Pennac, Michou, Amis, Fowles, Barnes, McEwan, Byatt, Banville, Ishiguru, Kureishi, Rushdie, Ondaatje, Borges, Cortázar, Bolaño, Saramago, Marías, VilaMatas, Bernhard, Jelinek, Hrabal, Kertesz, Kazakov, Murakami, Altman, Coen etc. e, na Itália, Eco, Calvino, Tabucchi e Tondelli (CESERANI, 2012, p. 212).

O último ponto que gostaríamos de destacar no texto de Ceserani é que ele ainda considera que Donnarumma cai em contradição ao usar a categoria de hipermodernidade de Lipovetsky e que, no fim, acaba por pregar um impossível retorno à modernidade. Ao dizer que o hipermoderno substitui o pós-moderno, Donnarumma teria se dado conta de que as definições encontradas no filósofo francês são equivalentes àquelas de Frederic Jameson (1984) para o pós-moderno e, assim, precisaria dizer que o hipermoderno "não marca uma fratura clara, violenta e polêmica em relação ao pós-moderno, como queria ter feito, justamente, o pós-moderno em relação à 
modernidade, mas é uma variante [do pós-moderno] e pode até se sobrepor a ele [...]" (DONNARUMMA, 2011, p. 19, tradução nossa). Além de confirmar a confusão entre os termos pósmoderno e pós-modernismo, essa espécie de dialética às avessas seria a saída para Donnarumma perante as crises do tempo presente, retomando aos projetos "esperançosos" e "interruptos" da modernidade com a nova roupagem do presente; seria lindo, conclui ironicamente Ceserani (2012).

O debate entre Remo Ceserani e Raffaelle Donnarumma, no entanto, não termina com La maledizione degli "ismi": no $n^{\circ} 67$ de Allegoria, Donnarumma faz uma réplica ainda mais irônica e incisiva para defender o seu ponto de vista, primeiramente esclarecendo que, contrariamente ao que diz Ceserani, ele não considera que o pós-modernismo seja um fenômeno negativo, mas que vê nele uma exaustão e uma contradição entre "um excepcional impulso de liberdade em todos os campos que atravessou [...]" (DONNARUMMA, 2013, p. 186, tradução nossa) e uma suspensão de si mesmo. Sua falta de entusiasmo pela cultura pós-moderna se dá pelo fato de que, apesar de ter nascido e se formado durante o pós-moderno e ter tido acesso às suas referências, aqueles escritores "estavam muito longe da [sua] experiência do presente, tão remotos das [suas] necessidades culturais [...]" (DONNARUMMA, 2013, p. 188, tradução nossa); apesar de bela, aquela literatura era marcada pela cultura do fim (fim da história, fim da experiência e fim do "eu"), que ia de encontro ao que se vivia, da experiência que continuava a produzir-se. Para Donnarumma, enquanto os anos 1970 foram marcados por crises e por violência, os escritores, que eram partícipes dessa convulsão social como indivíduos, preferiam ficar fora do debate público a escrever sobre 
"castelos dos destinos cruzados, de adediretti, ${ }^{4}$ de bibliotecas conventuais, de jogos ao avesso." (DONNARUMMA, 2013, p. 189, tradução nossa). A crítica continua fazendo uma clara referência a Italo Calvino (1923-1985) ao falar do descolamento do real naquela literatura, uma ilusão de que, ao concentrar-se na escritura e refletir sobre ela mesma, buscando um trabalho de experimentação e metalinguística, acabar-se-ia por cair na autorreferencialidade, querendo-se criar um lugar outro que colocasse as contradições do mundo em cena sem explicitálas diretamente: "Ninguém discute, digamos, que As Cidades Invisíveis fale sobre a revolução da vida associada pós 1968; mas a que serve o empenho que dá para decifrar um livro assim árduo?" (DONNARUMMA, 2013, p. 189, tradução nossa).

O segundo ponto a ser rebatido por Donnarummaé a acusação de que ele confundiria "pós-moderno" e "pós-modernismo", a qual é recebida com surpresa. Como já acenamos anteriormente, para o leitor que tem contato com esse debate pela primeira vez por meio do texto no $\mathrm{n}^{\mathrm{o}} 64$ de Allegoria, torna-se um pouco confuso o uso um tanto fluído dos termos "pós-moderno" e "pósmodernismo", levando a crer que há uma equivalência pacífica entre os termos. Porém, nessa ocasião, Donnarumma esclarece melhor a sua concepção retomando o texto precedente no $\mathrm{n}^{\circ} 57$ da mesma revista, em 2008, quando o crítico afirmara que "é o pós-moderno que se põe junto a poéticas e a práticas de escritura. Isso, por fim, não impede que alguns pós-modernistas continuem a sua estrada [...]. Muito menos implica que seja realmente finda a pós-modernidade entendida como fase da história ocidental [...]" (DONNARUMMA, 2008, p. 27, tradução nossa). Do mesmo modo, na réplica, volta a reafirmar a diferenciação terminológica

4 Referência à obra Hilarotragedia, de Giorgio Manganelli (1987). 
citando, inclusive, o próprio Ceserani (2012, p. 190), que propunha uma distinção tripla entre posmodernità como uma época histórica em voga desde os anos 1950; postmodernismo como uma produção artístico-cultural, e postmoderno como uma época plural que não constituiu uma poética em comum. Agora, no entanto, Donnarumma prefere o termo "era da globalização" para se referir ao tempo da contemporaneidade não mais como uma extensão do pós-moderno, pensando no uso que fazem Ceserani e Benvenuti no também já citado Letteratura nell'età globale (DONNARUMMA, 2013, p. 189).

Dito isso, o dissenso entre os críticos está na compreensão do pós-moderno como uma fratura, algo que Donnarumma, ao contrário de Ceserani, não compartilha: para ele, o pós-moderno não foi nada mais do que uma das tantas scansioni interne (variações internas) da Modernidade (DONNARUMMA, 2013, p. 195), entendida como período histórico. A ideia de scansioni reaparece em outros textos do autor e nos ajuda a compreender melhor a dinâmica do modernismo, pós-modernismo e (agora) hipermodernismo dentro de uma categoria historiográfica mais ampla. Um exemplo disso está na obra Ipermodernità, no capítulo reelaborado a partir do texto de 2011, em Allegoria $\mathrm{n}^{\circ}$ 64, no qual há uma passagem que esclarece a posição do autor fazendo uma advertência lexical e conceitual:

A minha hipótese é que o modernismo, o pós-moderno e o hipermoderno sejam as idades culturais nas quais se articula, em modos diversos, uma modernidade mutável e perdurante; do mesmo jeito em que românico e gótico, Humanismo e Renascimento, maneirismo e barroco são o desenrolar-se sucessivo, distinto e correlato, de um acontecimento maior que de tempos em tempos os engloba. A terminologia é defeituosa e não permite estabelecer simetrias biunívocas: a tríade pós-modernidade-pós-modernismo-pós-moderno 
não encontra, de fato, correspondência na tríade modernidade-modernismo-moderno, como já vimos. (DONNARUMMA, 2014a, p.116-117, tradução nossa).

Assim, se o pós-moderno é uma “etapa” da Modernidade, o discurso de Ceserani entraria em crise, pois não é possível que haja uma fratura de algo que representa uma variação interna de uma macrofase da história; ele anuncia que se saiu da modernidade e, ao mesmo tempo, busca em Zygmunt Bauman (2001) a definição de "modernidade líquida" para falar do tempo presente, caindo em uma circularidade do adjetivo que prova que, de fato, não saímos da Modernidade. Segundo Donnarumma, Ceserani não percebe isso porque assume uma postura "hermenêutica historicista [...] rígida" e porque "prevê de fato o alinhamento entre cultura e história [...]" (DONNARUMMA, 2013, p. 196, tradução nossa); sendo assim, não consegue distinguir o tempo presente daquele pós-moderno, o que lhe faria incorrer no risco de achar que "Saviano possa ser lido como Calvino, que para Philip Roth se possa adotar as mesmas categorias boas para Thomas Pynchon, que Houellebecq e Tournier sejam irmãos; se ele que é tão sensível e tão atento acha que respira, em 2013, o mesmo ar que respirava em 1983." (DONNARUMMA, 2013, p. 197, tradução nossa).

Fica mais evidente a posição de Donnarumma em relação à questão dos termos "pós-moderno" e "pós-modernismo", abrindo espaço, então, à sua escolha do hipermoderno. Ao contrário do que diz Ceserani, o crítico não está alinhado à acepção de Gilles Lipovetsky e Sebastian Charles, pois vê como incoerente a percepção dos autores de um otimismo que eles veem na crise do sujeito hipermoderno: esse "narciso" (LIPOVETSKY; CHARLES, 2004, p. 26) é hiperindividualista, 
mas, ao mesmo tempo, em seu individualismo, vê esperança no futuro e tem uma preocupação ecológica e com sua saúde (LIPOVETSKY; CHARLES, 2004, p. 72). Donnarumma não compartilha dessas categorias filosóficas e sociológicas porque, para ele, o que importa em primeiro plano é a discussão da literatura hipermoderna como categoria da crítica literária, e, nesse sentido, o prefixo "hiper-" lhe serve bem porque, ao contrário do "pós-", não marca uma ruptura com o modernismo e consegue expressar na literatura que "a narrativa contemporânea nos impõe [...] a tentativa de fazer experiência em um mundo tomado como traumático e ameaçador, mais do que perdido na indistinção entre o imaginário e o real." (DONNARUMMA, 2014a, p. 89, tradução nossa).

Dessa feita, outro ponto interessante que diferencia a perspectiva de Donnarumma é a de contrariar Ceserani em relação aos "ismos" ao dizer que não se preocupou tanto com o uso de ipermodernismo em vez de ipermoderno ou ipermodernità em seu livro Ipermodernità (2014a), pois essa discussão seria artificial já que, como crítico literário, seria óbvio que todas as suas reflexões fossem sobre literatura; é claro que ele não desconsidera o contexto, mas o que para Ceserani é primário, para ele é secundário: "Porém, o fato de que eu não me passe por sociólogo, economista, analista político ou filósofo não quer dizer que eu me furtarei da discussão desses problemas, que são indubitavelmente fundamentais, mas que Ceserani sente como prioritários (temo) em detrimento daqueles da minha (nossa?) disciplina." (DONNARUMMA, 2013, p. 191, tradução nossa).

Se o ataque às Torres Gêmeas de Nova York, em 11 de setembro de 2001, marca o início de um novo século e de uma nova era, a virada cultural e estética que marca os escritores dos 
"anos zero" e a literatura hipermoderna começara a maturar já na metade dos anos noventa do século XX com o exaurimento do pós-modernismo e com o impor-se de uma narrativa que contempla, sobretudo, o quotidiano; logo, as grandes transformações históricas "primárias", como diz Ceserani (2012), não necessariamente correspondem às grandes transformações literárias. De fato, Donnarumma é muito centrado em querer fazer a ponte entre literatura e mundo, e não o contrário, e suas declarações em relação a esse ponto de vista são consistentes, como, por exemplo, em La fatica dei concetti. Ipermodernità, postmoderno, realismo, de 2014: sempre categórico, afirma que o que the interessa é "aquilo que há dentro dos livros, mais e além daquilo que, de fora, ajuda-nos a entendê-los" [...] (DONNARUMMA, 2014b, p. 7, tradução nossa), entendendo como brutal a distinção do que a crítica vê como dentro e fora. Aprofundando a sua colocação, diz que a crítica literária italiana está em crise e que é necessário olhar mais para os livros do que para o que está entorno deles, porque, apesar disso ser de grande interesse aos "demônios da teoria", "ninguém compra um romance perguntando-se qual é a profissão dos autores ou sobre a geografia das editoras [...]" (DONNARUMMA, 2014b, p. 8 , tradução nossa).

Aproveitando o ensejo de La fatica dei concetti e para fechar a questão da razão pela qual Donnarumma prefere "hiper-", vemos que, quando o crítico percebeu que precisava de um novo nome para uma nova expressão literária na contemporaneidade, ele buscou outros termos até chegar ao de Lipovetsky e explica o motivo da escolha:

Quando se tratou de batizar o pós-moderno, eu precisava de um nome que insistisse na persistência da modernidade e que também me permitisse liga- 
lo à questão do realismo. Não havia muitíssimas alternativas: já expliquei como a modernidade líquida de Bauman (com quem aprendi mais do que com Lipovetsky, para ser sincero) não me satisfazia, visto que o adjetivo, mesmo contra ele, faz pensar em um atenuar-se das tensões; surmodernidade de Augé diz pouco, e teria levado consigo o hóspede fora do lugar que é o surrealismo; a segunda modernidade de Beck ultrapassava as contas, visto que as fases culturais que individuo (modernismo, pós-moderno, hipermoderno) são três. Logo, e por que (afeiçoado que sou à navalha de Occam) não acho que seja o caso de entupir a discussão com palavras novas, a escolha caiu em hipermodernidade, cujo prefixo excessivo e ansiógeno me serve. (DONNARUMMA, 2014b, p. 2, tradução nossa).

Além disso, é importante precisar que, ao agradecer a Valentino Baldi por dizer que o seu coração "não só [...] bate mais pelo modernismo que pelo realismo [...]" (DONNARUMMA, 2014b, p. 6, tradução nossa), Donnarumma não faz apologia ao modernismo e nem quer que "hiper-" represente uma exaltação do moderno, pois ele bem sabe que "o hipermoderno, que abandonou a fé moderna, não acredita nas suas promessas de felicidade até o fim. Ele é uma compulsão neurótica que neutraliza os seus ídolos (rapidez, novidade, eficiência, agilidade...) ao mesmo tempo que os eleva [...]" (DONNARUMMA, 2014a, p. 104, tradução nossa). E ainda: “é aqui, então, que o hipermoderno retoma a vontade crítica e autocorretiva da modernidade, mas sabendo que nenhuma revolução é mais possível [...]" (DONNARUMMA, 2014a, p. 105, tradução nossa), dado o esfacelamento e a impossibilidade do pós-moderno de ter dado uma resposta ao seu tempo.

Também Donnarumma, em Tracciato del Modernismo Italiano (DONNARUMMA, 2012), diz que, ao contrário dos 
vanguardistas da primeira metade do século $\mathrm{XX}$, "a postura modernista é [...] crítica e dialética, e oscila entre a nostalgia e a utopia." (DONNARUMMA, 2012, p.16, tradução nossa). Os modernistas se aproveitariam do ímpeto de inovação dos vanguardistas para quebrar paradigmas, mas sempre indo além, buscando refletir sobre os clássicos e valorizando a forma: a narrativa modernista busca a fidelidade ao mundo para desnudá-lo e expor as suas contradições e aquilo que até então era considerado vil, irrelevante, mundano (DONNARUMMA, 2012); no entanto o realismo não é uma lente, um espelho, como para os realistas do século XIX, pois, para um modernista, só faz sentido enquadrar a realidade em uma forma:

Para um modernista, ao contrário, a coisa narrada existe somente na forma que a conta. As palavras nunca são inocentes ou "virgens", como diz Gadda, porque trazem em si impressões históricas e subjetivas; ou porque, no limite, como astutamente assume Zeno, nós sempre "mentimos" [usando as palavras]: "entende-se como a nossa vida teria um aspecto totalmente diferente se fosse contada em nosso dialeto", ou seja, em outra forma. (DONNARUMMA, 2012, p. 26, tradução nossa)

Por isso, a forma é um artifício que serve à mediação entre o mundo e a escrita, o que não quer dizer ser mentirosa, porque sem as instâncias de realidade e verdade "perderia todo o próprio significado [...]" (DONNARUMMA, 2012, p. 26, tradução nossa). Donnarumma cita o romance A consciência de Zeno (1923), de Italo Svevo (1861-1928), a título de exemplificação, pois o escritor triestino usa a categoria da psicanálise para criar a sua narrativa, ou seja, utiliza de um saber extraliterário como verdade/realidade para dar uma forma a uma ficção. Essa seria a diferença entre a autorreflexividade modernista e a autorrerefencialidade pós-modernista: enquanto que, no 
primeiro caso, "trazer à luz os artifícios significa mostrar o valor da mediação, e até as responsabilidades da veracidade [...]", no segundo, acaba-se por "enrola-se em um jogo de espelhos no qual a escritura fala de si [...]” (DONNARUMMA, 2012, p. 26, tradução nossa).

\section{Considerações finais}

Como conclusão, podemos dizer que, das distinções e perspectivas que traçamos a partir do debate entre Remo Ceserani e Raffaele Donnarumma, parece-nos que a abordagem do segundo autor expressa melhor uma constante que se configura no panorama literário italiano contemporâneo, que se configura a partir de: um retorno ao realismo como estética; o noir como expressão do degradado; a reabilitação da voz narrativa em primeira pessoa, ou seja, do "eu" como testemunha e partícipe dos fatos, mesmo que a sua condição de fragilidade deponha contra ele e quebre o estatuto de veracidade entre ele e o leitor, e o limiar entre ficção e não ficção, derivando ao gênero da autoficção (DONNARUMMA, 2014a). Obviamente, para demonstrar essas características, seria necessário um estudo de corpus da literatura italiana contemporânea, mas, somente do que citamos, percebe-se que esses "sintomas" de uma nova literatura partem da mesma necessidade de encontrar uma forma para o desamparo do sujeito em um mundo dilacerado, assim como fora no século XX. Donnarumma não deixa de considerar as relações entre texto e contexto, mas é claro em sua posição de centrar a sua análise na literatura, seu ponto de partida e de chegada. 
Convém destacar, contudo, que as reflexões não se excluem e também colaboram entre si, e prova disso é que muito do que diz Ceserani (especialmente com Benvenuti) se encontra com as avaliações de Lipovetsky no sentido de reconhecerem no tempo presente uma crise, um domínio da lógica de consumo, uma globalização feroz. Desse modo, fica claro compreender como esse cenário agressivo influi no imaginário, e é por isso que Donnarumma aponta para a necessidade de um retorno do sujeito na forma de expressão literária: retorno ao real; retorno do eu como voz da narrativa e como testemunha; retorno da narrativa como forma, levando à recuperação do romance e, até mesmo, ao seu esgotamento etc.

Todas essas pistas levam aos leitores e estudiosos brasileiros a se questionarem: é possível dizer que a literatura brasileira contemporânea também seja hipermoderna nos termos de Raffaele Donnarumma? Se sim, quais traços/"sintomas" dos modernismos do século XX retornam nos dias de hoje? A teoria do crítico italiano é aplicável à realidade brasileira? São perguntas que se abrem a um debate que, ainda, não ganhou força em nosso país.

\section{Referências}

BAUMAN, Zygmunt. Modernidade líquida. Tradução de Plínio Dentzien. Rio de Janeiro: Jorge Zahar Ed., 2001.

BENVENUTI, Giuliana, CESARANI, Remo. La letteratura nell'età globale. Bolonha: Il Mulino, 2012.

BRIOSCHI, Franco et al. Introduzione alla letteratura. 2. ed. Roma: Carocci editore, 2013. 
CESARANI, Remo. La maledizione degli "ismi". Allegoria, Palermo: G.b. Palumbo \& C. Editore S.p.a., n. 65-66, p. 191213, 2012. Disponível em: https://www.allegoriaonline.it/index. php/i-numeri-precedenti/allegoria-n65-66. Acesso em: 28 ago. 2021.

DONNARUMMA, Raffaele; POLICASTRO, Gilda (org.). Ritorno alla realtà? Otto interviste a narratori italiani. Allegoria, Palermo: G.b. Palumbo \& C. Editore S.p.a., n. 57, p. 9-25, 2008. Disponível em: https://www.allegoriaonline.it/index.php/inumeri-precedenti/allegoria-n57. Acesso em: 21 mar. 2021.

DONNARUMMA, Raffaele. Ipermodernità: ipotesi per un congedo del postmoderno. Allegoria, Palermo: G.b. Palumbo \& C. Editore S.p.a., n. 64, p. 15-50, 2011. Disponível em: https://www.allegoriaonline.it/index.php/i-numeri-precedenti/ allegoria-n64. Acesso em: 28 ago. 2021.

DONNARUMMA, Raffaele. Tracciato del Modernismo Italiano. In: LUPERINI, Romano; TORTORA, Massimiliano (org.). Sul Modernismo Italiano. Nápoles: Liguori Editore, 2012.

DONNARUMMA, Raffaele. Il faut être absolument hypermodernes. Una replica a Remo Ceserani. Allegoria, Palermo: G.b. Palumbo \& C. Editore S.p.a., n. 67, p. 185-199, 2013. Disponível em: https://www.allegoriaonline.it/index.php/ i-numeri-precedenti/allegoria-n67. Acesso em: 29 ago. 2021.

DONNARUMMA, Raffaele. Ipermodernità: dove va la narrativa contemporanea. Bolonha: Il Mulino, 2014a.

DONNARUMMA, Raffaele. La fatica dei concetti. Ipermodernità, postmoderno, realismo. Between, v. IV, n. 8, 2014b.

JAMESON, F. Postmodernism or the Cultural Logic of Late Capitalism. New Left Review, n. 146, p. 59-92, July/Aug. 1984. LIPOVETSKY, Gilles; CHARLES, Sebastian. Os tempos 
hipermodernos. Tradução de Mário Vilela. São Paulo: Barcarolla, 2004.

PERASSO, Valeria. O que é a $4^{\mathrm{a}}$ revolução industrial - e como ela deve afetar nossas vidas. BBC Brasil, São Paulo, 22 out. 2016. Disponível em: https://www.bbc.com/portuguese/ geral-37658309. Acesso em: 29 ago. 2021.

ROSENFELD, Anatol. Reflexões sobre o romance moderno. In: ROSENFELD, Anatol. Texto/Contexto I. 5. ed. São Paulo: Perspectiva, 2009. p. 75-97. 